\title{
Justiça social e cidadania ambiental como mecanismos de enfrentamento da crise habitacional
}

\author{
Social justice and environmental citizenship as coping mechanisms for the \\ housing crisis
}

\author{
Justicia social y ciudadanía ambiental como mecanismos de \\ enfrentamiento a la crisis de la vivenda
}

\section{Daiane Acosta Amaral ${ }^{1}$ David Silva de Souza ${ }^{2}$}

\begin{abstract}
Resumo
O rápido crescimento das aglomerações urbanas é resultado de um processo histórico de urbanização que se intensificou a partir de meados do século XX. A urbanização crescente deverá ser acompanhada do aumento da pobreza e, como já se sabe, os impactos da combinação de tais processos serão de toda ordem, sobretudo ambiental e social.Assim, em que pesem as parcas políticas públicas voltadas para a inclusão social e da inércia estatal em procurar soluções imparciais para os dilemas da precariedade urbana, cabe à coletividade também buscar o equilíbrio socioambiental, de modo que as ações sejam revestidas de obrigação intergeracional, ou seja, com respeito à geração futura.A cobrança de ações efetivas passa pelo reconhecimento da participação social de cada indivíduo e da relação de pertencimento com a sociedade.
\end{abstract}

Palavras-Chave: Justiça- Habitação - Ambiente

\section{Resumen}

El rápido crecimiento de las aglomeraciones urbanas es el resultado de un proceso histórico de urbanización que se intensificó a mediados del siglo XX. La urbanización creciente debe ir acompañada del aumento de la pobreza y, como ya se sabe, los impactos de la combinación de tales procesos serán de todo orden, sobre todo ambiental y social. Así, en que pesen las parcas políticas públicas orientadas hacia la inclusión social y la inercia estatal en buscar soluciones imparciales para los dilemas de la precariedad urbana, cabe a la colectividad también buscar el equilibrio socioambiental, de modo que las acciones estén revestidas de obligación intergeneracional, o con respecto a la generación futura. El cobro de acciones efectivas pasa por el reconocimiento de la participación social de cada individuo y de la relación de pertenencia con la sociedad.

Palabras claves: Justicia - Vivienda - Medio ambiente

\begin{abstract}
The rapid growth of urban agglomerations is the result of a historical process of urbanization that has intensified since the mid-twentieth century. Increasing urbanization must be accompanied by increased poverty and, as we know, the impacts of combining such processes will be of all order, especially environmental and social. Thus, in spite of weak public policies aimed at social inclusion and state inertia in seeking impartial solutions to the dilemmas of urban precariousness, it is also up to the collectivity to seek social and environmental balance, so that actions are covered by intergenerational obligation, or with respect to the future generation. The collection

\footnotetext{
${ }^{1}$ Mestra em Direito e Justiça Social, pelo Programa de Pós-Graduação em Direito e Justiça Social, da Universidade Federal do Rio Grande - FURG, Rio Grande Rio Grande do Sul. E-mail: daia_acostamaral@hotmail.com

2 Doutorando em Educação Ambiental, pelo Programa de Pós-Graduação em Educação Ambiental, da Universidade Federal do Rio Grande - FURG, Rio Grande Rio Grande do Sul. E-mail: davidsouza22@gmail.com
} 
of effective actions involves the recognition of the social participation of each individual and the relation of belonging with society.

Keywords: Justice - Housing - Environment

\title{
1. Introdução
}

A cidade é o lugar em que o ser humano se aglomera densamente, uma realidade que não tem retorno. Segundo o Relatório do Fundo de População das Nações Unidas em 2008, até 2030, as cidades do mundo em desenvolvimento responderão por $80 \%$ da população urbana. (MEDEIROS, 2011, p. 201)

No início do século XX, devido à rápida industrialização, as cidades atraíram grande parte da população, porém, inexistiam políticas habitacionais que impedissem a formação de áreas urbanas irregulares e ilegais. As áreas ocupadas ilegalmente são expressões diretas da ausência de políticas de habitação social. As políticas habitacionais propostas foram, em sua maioria, ineficazes devido a diversos fatores políticos, sociais, econômicos e culturais. (HOLZ; MONTEIRO, 2008)

As ocupações ilegais e irregulares estão presentes na maioria dos municípios brasileiros, escancarando uma triste realidade social: a da falta de moradia. Porém, o problema não é apenas a falta de imóveis para morar, mas também a ausência de posse segura, que por sua vez faz favorece a péssima qualidade com que são construídos os que existem, em especial nas áreas ilegais. $\mathrm{O}$ acesso informal ao solo e consequentemente à moradia é um dos maiores problemas das últimas décadas, fortemente agravado pela falta (intencional) de políticas habitacionais adequadas para atender a população mais carente. (HOLZ; MONTEIRO, 2008)

Assim:

\begin{abstract}
A urbanização desigual e combinada das cidades coloca em evidência a questão do acesso a moradia digna como uma das principais demandas sociais nos países periféricos. A questão urbana no Brasil está longe de ser resolvida, sendo que o déficit habitacional brasileiro e a existência de uma significativa parcela da população vivendo em favelas e outras formas de assentamentos ilegais estão no centro da chamada crise urbana. Neste contexto surge o debate sobre a necessidade da reforma urbana, bandeira levantada por uma parte importante do movimento social urbano (STEFANIAK, 2012, p. 68).
\end{abstract}

A origem das cidades se deu a partir das mudanças da organização produtiva, ao passo que a mencionada organização transformou o cotidiano dos indivíduos, tendo como consequência o desenvolvimento demográfico. 
Não obstante, o Direito Urbanístico surge como instrumento para o equilíbrio ambiental, através de dispositivos ambientais que delimitam os espaços construídos e habitáveis pela pessoa humana, salvaguardando a função social da propriedade e a dignidade da pessoa humana.

Neste contexto, no Direito Ambiental Brasileiro o constituinte originário se preocupou em inovar também ao dispor sobre Política Urbana.

Logo, os artigos 182 e 183, da Constituição Federal de 1988 compõem um dos capítulos do importante Título VII cujo conteúdo é a Ordem Econômica e Financeira. Cabe destacar que foi a primeira constituição a tratar sobre o planejamento urbano, sendo que criou novos e importantes institutos e instrumentos para o alcance da função social da propriedade.

Neste contexto, a cidade é o habitat do ser humano, o ambiente urbano, ou artificial, é representado pelas cidades, entendidas como aglomerações humanas dotadas de edificações e infraestrutura consistente em áreas de lazer, serviços públicos, saneamento, etc (MARQUES, 2005, p. 52).

A principal regulamentação da política urbana ocorreu com a edição da Lei $n^{\circ}$ 10.257/2001, denominada Estatuto da Cidade.Tal legislação refere-se ao principal instrumento normativo de ordenação dos instrumentos constitucionais e de intervenção urbanística e fundiária nas cidades. Segundo Fabiano Melo Gonçalves de Oliveira (2012) o Estatuto estabelece normas de ordem pública e interesse em prol do bem coletivo, da segurança e do bem-estar dos cidadãos, bem como do equilíbrio ambiental. Em síntese, o objetivo da política urbana é ordenar o pleno desenvolvimento das funções sociais da cidade e da propriedade urbana.

Não obstante para a efetividade de política constitucional de desenvolvimento urbano passa pela inserção da função social da propriedade como mecanismo garantidor da proteção possessória.

No que tange a função social descrita na Constituição Federal de 1988, José Afonso da Silva aduz que:

Cada qual desses tipos pode estar sujeito, e por regra estará, a uma disciplina particular, especialmente porque, em relação a eles, o princípio da função social atua diversamente, tendo em vista a destinação do bem objeto da propriedade. Tudo isso, aliás, não é difícil de entender, desde que tenhamos em mente que o regime jurídico da propriedade não é uma função do Direito Civil, mas de um complexo de normas administrativas, urbanísticas, 
empresariais (comerciais) e civis (certamente), sob fundamento das normas constitucionais. (SILVA,1997, p. 266)

Vale destacar que o direito à propriedade possui dupla acepção jurídica, uma garantia social e outra de acesso. Corrobora neste entendimento Luiz Edson Fachin:

A ideia de interesse social corresponde ao início da distribuição de cargas sociais, ou seja, da previsão de que ao direito subjetivo da apropriação também correspondem deveres. Nessa esteira, passa-se a entender que esse direito subjetivo tem destinatários no conjunto da sociedade, de modo que o direito de propriedade também começa a ser lido como direito à propriedade. Gera, por conseguinte, um duplo estatuto: um de garantia, vinculado aos ditames sociais, e outro, de acesso. (FACHIN, 2003, p. 289)

\title{
2. Crise habitacional e o direito à moradia
}

Nota-se que a consagração do Estado Social de Direito e do Estado Socioambiental, com fulcro na Constituição Federal de 1988, trata à propriedade sob ótica que ultrapassa as matrizes formais do liberalismo, em que o ordenamento tutela a propriedade privada desde que esta efetivamente cumpra a função social.

Assim, preceitua Eros Roberto Grau:

\begin{abstract}
Não se pretende, nisso, atribuir ao Judiciário o desempenho de funções que são próprias do Legislativo - ou seja, a de produção de ato legislativo - ou mesmo do Executivo - ou seja, a de produção do ato administrativo. O que se sustenta - e, no caso, sob o manto do princípio da supremacia da Constituição - é, meramente, cumprir ao Poder Judiciário assegurar a pronta exeqüibilidade de direito ou garantia constitucional imediatamente aplicável, dever que se lhe impõe e mercê do qual the é atribuído o poder, na autorização que para tanto recebe, de, em cada decisão que a esse respeito tomar, produzir direito (..) (GRAU, 1997, p. 336-337)
\end{abstract}

Ademais o real cumprimento da função social de uma propriedade urbana pode-se verificar nas previsões contidas no plano diretor do Município.

Neste sentido, os parágrafos $3^{\circ}$ e $4^{\circ}$ do artigo 182 da Constituição Federal de 1988, dispõe:

Art.182 - A política de desenvolvimento urbano, executada pelo Poder Público municipal, conforme diretrizes gerais fixadas em lei, tem por objetivo ordenar o pleno desenvolvimento das funções sociais da cidade e garantir o bem-estar de seus habitantes.

$\$^{\mathbf{o}}$ - As desapropriações de imóveis urbanos serão feitas com prévia e justa indenização em dinheiro.

$\$ \mathbf{4}^{\mathbf{0}}$ - É facultado ao Poder Público municipal, mediante lei específica para área incluída no plano diretor, exigir, nos termos da lei federal, do proprietário do solo urbano não edificado, subutilizado ou não utilizado, que promova seu adequado aproveitamento, sob pena, sucessivamente, de:

I - parcelamento ou edificação compulsórios; 
II - imposto sobre a propriedade predial e territorial urbana progressivo no tempo; III - desapropriação com pagamento mediante títulos da dívida pública de emissão previamente aprovada pelo Senado Federal, com prazo de resgate de até dez anos, em parcelas anuais, iguais e sucessivas, assegurados o valor real da indenização e os juros legais.

Destarte, a função social da propriedadeintegra as chamadas cláusulas pétreas, ou seja, aquelas que não podem ser objeto de emenda, nos termos do artigo $60, \S 4^{\circ}$ da Constituição, a saber:

$\$^{\mathbf{0}}$ - Não será objeto de deliberação a proposta de emenda tendente a abolir:

I - a forma federativa de Estado;

II - o voto direto, secreto, universal e periódico;

III - a separação dos Poderes;

IV - os direitos e garantias individuais.

Vale salientar que os instrumentos descritos nos dispositivos supracitados foram regulamentados pela Lei 10.257/2001, denominado Estatuto da Cidade.

Já o artigo 183, trata da usucapião especial, a saber:

Art.183 - Aquele que possuir como sua área urbana de até duzentos e cinqüenta metros quadrados, por cinco anos, ininterruptamente e sem oposição, utilizando-a para sua moradia ou de sua família, adquirir-lhe-á o domínio, desde que não seja proprietário de outro imóvel urbano ou rural.

\$1 $\mathbf{1}^{\mathbf{0}}$ - O título de domínio e a concessão de uso serão conferidos ao homem ou à mulher, ou a ambos, independentemente do estado civil.

$\$ 2^{\circ}$ - Esse direito não será reconhecido ao mesmo possuidor mais de uma vez.

$\$^{\circ}$ - Os imóveis públicos não serão adquiridos por usucapião.

Também o Código Civil de 2002 expressa a redefinição do conteúdo do direito da propriedade à luz dos valores constitucionais ecológicos ou socioambientais, tendo em conta a carga de deveres e obrigações correlatas ao seu exercício(FENSTERSEITFER, 2008, p. 209).

Neste sentido, o $\S 1^{\circ}$ do artigo 1228 do Código Civil de 2002, estabelece:

Art. 1.228. O proprietário tem a faculdade de usar, gozar e dispor da coisa, e o direito de reavê-la do poder de quem quer que injustamente a possua ou detenha.

§ $\mathbf{1}^{\circ} \mathrm{O}$ direito de propriedade deve ser exercido em consonância com as suas finalidades econômicas e sociais e de modo que sejam preservados, de conformidade com o estabelecido em lei especial, a flora, a fauna, as belezas naturais, o equilíbrio ecológico e o patrimônio histórico e artístico, bem como evitada a poluição do ar e das águas.

Em suma o Estatuto da Cidade revela-se fundamental na fixação do cumprimento da função social e ambiental da propriedade urbana. 
Cabe destacar que para a Geografia Crítica o lugar passa de mero espaço vivido para a identificação da construção social. Neste sentido, apoiam tal assertiva Carlos (1996), Harvey (1996) e Santos (1994).

No entendimento de Santos (1994) tudo que existe num lugar está em relação com os outros elementos desse lugar. O que define o lugar é exatamente uma teia de objetos e ações com causa e efeito, que forma um contexto e atinge todas, as variáveis já existentes, internas, e as novas que vão internalizar (SANTOS, 1994, p. 97).

Seguindo essa premissa, Santos, define espaço como:

(...) um conjunto de objetos e de relações que se realizam sobre estes objetos; não entre estes especificadamente, mas para as quais eles servem de intermediários. Os objetos ajudam a concretizar uma série de relações. O espaço é o resultado da ação do homem sobre o próprio espaço, intermediando pelos objetos, naturais e artificiais (SANTOS, 1988, p. 71)

Para Harvey (1996), o "lugar se trata de uma construção social de permanências relativas internamente heterogêneas, dialéticas, dinâmicas contidas na dinâmica geral de espaço-tempo de processos sociológicos" (HARVEY apud FERREIA, 2001, p. 7).

Carlos (1996) compreende que o lugar é a sustentação da reprodução da vida, com a tríade habitante-lugar-identidade, em um período ditado pela globalização.

Não obstante o bairro é um lugar em que há laços de identidade, que traduzem o cotidiano e o modo de vida, um sentido de uso.

O lugar só pode ser compreendido em suas referências, que não são específicas de uma função ou de uma forma, mas de um conjunto de sentidos e usos. Assim, o lugar permite pensar o viver, o habitar, o trabalho, o lazer enquanto situações vividas, revelando, no nível do cotidiano, os conflitos que ocorrem ou ocorreram no mundo (CARLOS. 1996, p. 21-22).

Lefrebvre apud Carlos (1996, p.31) aponta que:

Os lugares tanto se opõem como se completam ou se reúnem o que introduz uma classificação por topias (isopias, heteropias, utopias, quer dizer lugares contrastantes), mas também e, sobretudo, uma oposição altamente pertinente entre os espaços dominados e apropriados.

Assim, o bairro como nível da prática socioespacial se revela no plano vivido (envolvendo a categoria habitante), que mostra da reprodução especial no mundo moderno (...) nessa dimensão concreta, ocorre a produção de laços de solidariedade e união dos habitantes (CARLOS, 2001, p. 244).

Em síntese, o lugar revela a solidariedade e o conflito, o conformismo e a mudança, ditados pelas forças internas e externas do mundo, ou seja, o lugar é onde estão os homens 
juntos, sentidos, vivendo, pensando, emocionando-se (SANTOS apud ARROYO, p. 1996, p.59).

Para Lefebvre, o direito à cidade se refere ao direito e experimentos e usufruir da centralidade urbana ${ }^{3}$ com base no valor de uso, assim é o direito:

(...) à vida urbana, à centralidade renovada, aos locais de encontro e de trocas, aos ritmos de vida e empregos do tempo que permitem o uso pleno e inteiro desses momentos e locais etc. (...) A proclamação e a realização da vida urbana como reino do uso (da troca e do encontro separados do valor de troca), exigem o domínio do econômico/ do valor de troca, do mercado e da mercadoria)"(LEFREBVRE, 2008, p. 139).

Mariato aduz que as classes populares tem direito à ocupação (ou moradia), mas não o direito à cidade (MARIATO, 1996, p. 63), o que revela a convivência do poder público em relação às ocupações irregulares que procuram a grosso modo evitar tensões urbanas, todavia tais áreas não podem ser objetos do mercado privado de habitação (MARIATO, 2010).

Segundo dados do Ministério das Cidades, o Programa Minha Casa Minha Vida beneficiou 73.618 pessoas no Rio Grande do Sul, sendo 740 beneficiários na Cidade do Rio Grande/ $\mathrm{RS}^{4}$, todavia tais números são insuficientes frente ao déficit habitacional existente.

Conforme censo demográfico de $2010^{5}$ o Brasil possui um déficit ${ }^{6}$ habitacional de 6,490 milhões de unidades, o correspondente a $12,1 \%$ do total de domicílios no país. Cerca de $70 \%$ deste estão localizados nas regiões Sudeste e Nordeste ${ }^{7}$.

Figura2. Déficit Habitacional- Censo 2010.

\footnotetext{
3"A vida urbana pressupõe encontros, confrontos das diferenças, conhecimentos e reconhecimentos recíprocos (inclusive no confronto ideológico e político) dos modos de viver, dos 'padrões' que coexistem na cidade" (LEFEBVRE, 2008, p. 22)

${ }^{4}$ Nesta consulta constam os beneficiários que receberam unidades habitacionais executadas pelo PMCMV Empresas, PMCMV - Entidades, PMCMV - Rural Grupo 1 e PMCMV - Oferta Pública até junho de 2015, com base nas informações disponibilizadas pelas Instituições Financeiras. Dados Disponível em http://www.cidades.gov.br/habitacao-cidades/programa-minha-casa-minha-vida-pmcmv/2014-11-19-13-55-23, acesso em 02 nov. 2015.

${ }^{5}$ No censo demográfico 2010, a identificação das famílias conviventes secundárias não foi feita no momento da entrevista. A coleta de informações limitou-se a identificar o responsável pelo domicílio e a relação de convivência dos demais moradores com ele. Posteriormente, o IBGE desenvolveu um algoritmo que permitiu identificar, de forma indireta, as famílias conviventes secundárias (Déficit habitacional Municipal no Brasil, 2013, p. 16).

${ }^{6} \mathrm{O}$ conceito de déficit habitacional utilizado está ligado diretamente às deficiências do estoque de moradias. Engloba aquelas sem condições de serem habitadas em razão da precariedade das construções e que, por isso, devem ser repostas. Inclui ainda a necessidade de incremento do estoque, em função da coabitação familiar forçada (famílias que pretendem constituir um domicílio unifamiliar), dos moradores de baixa renda com dificuldades de pagar aluguel e dos que vivem em casas e apartamentos alugados com grande densidade. Incluise ainda nessa rubrica a moradia em imóveis e locais com fins não residenciais. O déficit habitacional pode ser entendido, portanto, como déficit por reposição de estoque e déficit por incremento de estoque. (Déficit habitacional Municipal no Brasil, 2013, p. 14).

${ }^{7}$ Disponível em http://www.urbanismo.mppr.mp.br/modules/noticias/article.php?storyid=63 acesso em 02 nov. 2015.
} 


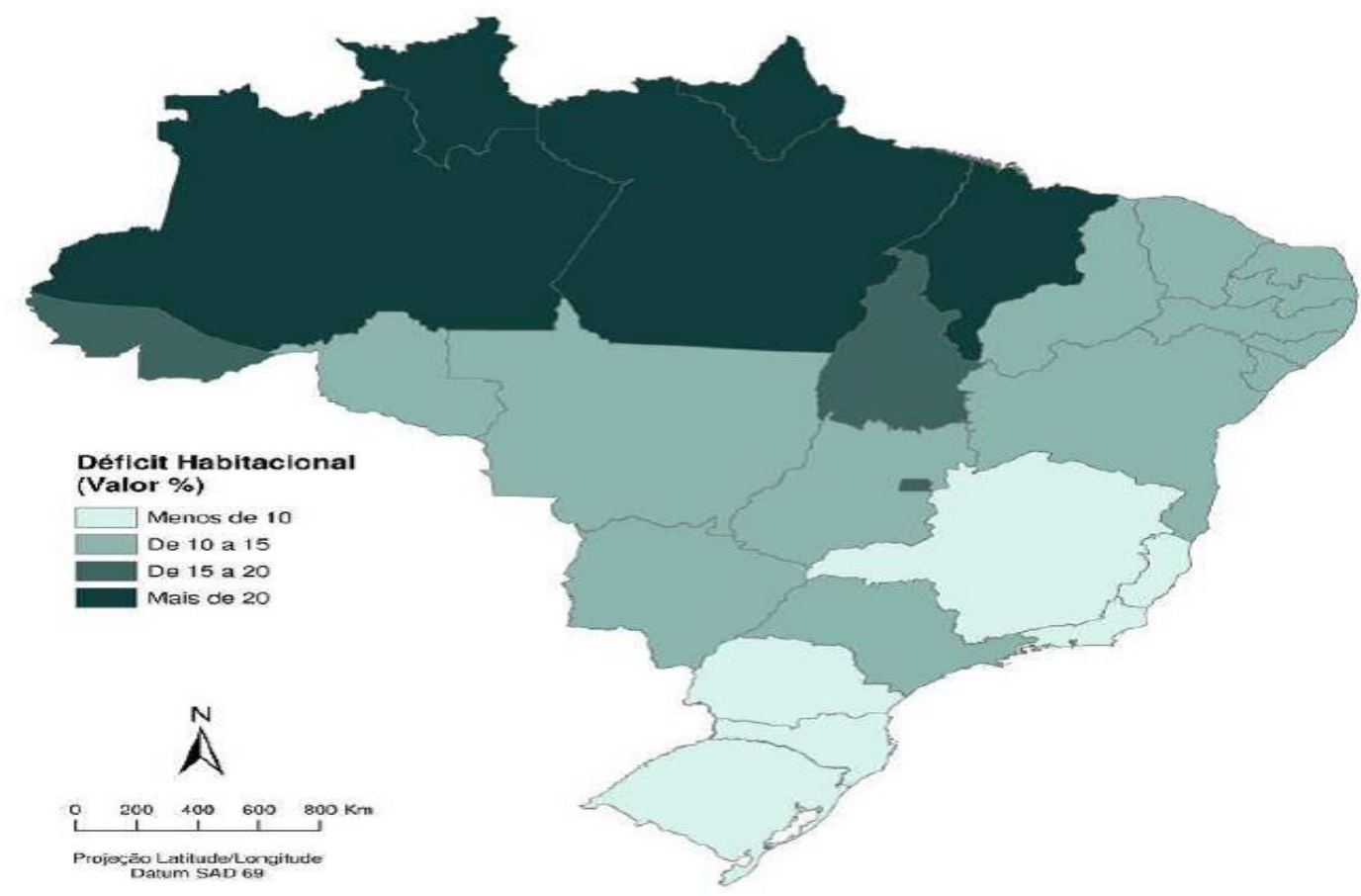

Fonte: Fundação João Pinheiro (FJP). Centro de Estatística e Informações (CEI).

Conforme dados do censo de 2010, a região Norte é a que apresenta os maiores (piores) resultados. Na região, 20,6\% dos domicílios se enquadra em algum critério de déficit e em todas as unidades da Federação o déficit habitacional relativo é maior que o observado para o total do país $(12,1 \%)$. O Maranhão apresenta o maior déficit habitacional relativo do país, de 27,3. Esse valor é 13 pontos percentuais acima da média da região Nordeste, que possui déficit relativo de 14,1 A região Sul é a que apresenta o menor déficit habitacional relativo do país $(8,7)$. Nos três estados da região, o déficit habitacional é inferior a 10\%. Em termos relativos, a região Sudeste também tem média inferior à do Brasil. O déficit habitacional relativo é de 10,6, média puxada pelo estado de São Paulo, com 11,6. Minas Gerais, Espírito Santo e Rio de Janeiro possuem déficit habitacional relativo inferior a $10 . \mathrm{Na}$ região Centro-Oeste, o déficit habitacional relativo é de 12,9, com destaque para o Distrito Federal $(16,9)^{8}$.

Quanto à infraestrutura urbana, o censo de 2010 revelou que a carência de infraestrutura urbana é o componente da inadequação que mais afeta os domicílios urbanos. No Brasil, 13 milhões de domicílios urbanos (26,4\%) carecem de pelo menos um item de infraestrutura básica: água, energia elétrica, esgotamento sanitário ou coleta de lixo. Os resultados mostram que a região Nordeste é a que possui o maior número de domicílios

${ }^{8}$ (Déficit habitacional Municipal no Brasil, 2013, p. 28). 
particulares permanentes urbanos com alguma carência de infraestrutura (4,8 milhões). A região Sudeste aparece em segundo lugar em número de domicílios (2,7 milhões). Nas regiões Norte, Sul e Centro-Oeste, o número de domicílios carentes está entre 1,6 e 1,9 milhões. Os estados do Rio de Janeiro e Bahia possuem o maior número de domicílios nessa situação, pouco mais de 1 milhão. Quando os números são comparados ao total de domicílios particulares permanentes da unidade de análise, a região Norte aparece com os piores resultados: 63,1\% de seus domicílios são carentes de pelo menos um componente da infraestrutura. As regiões Nordeste e CentroOeste apresentam valores próximos, em torno de $43 \%$, enquanto as regiões Sul e Sudeste aparecem com 23,8\% e 11,7\% de domicílios carentes respectivamente. Os resultados indicam que, nos estados de Rondônia e Amapá, em 76\% dos domicílios falta um ou mais itens de infraestrutura. Na melhor situação estão os domicílios de São Paulo: 7,6\% apresentam pelo menos uma carência ${ }^{9}$.

Cabe destacar ainda que o censo demográfico 2010 aponta um total de 57,3 milhões de Domicilio Particular Permanente- DPP sendo 49,2 milhões nas áreas urbanas e 8,0 milhões nas áreas rurais. Pouco menos da metade dos $\mathrm{DPP}^{10}$ (27,5 milhões) estão localizado nas regiões metropolitanas.

Conforme dados da Câmara Brasileira da Indústria e Construção (CBIC $)^{11}$, com base dados estatísticos sobre o Déficit Habitacional Brasileiro segundo a Fundação João Pinheiro em parceria com o Ministério das Cidades, Banco Interamericano de Desenvolvimento (BID) e Programa das Nações Unidas para o Desenvolvimento (PNUD), o déficit habitacional em 2012 seria de 5.430.562no Brasil.

Nesteparticular, as políticas públicas habitacionais não conseguem resolver a questão habitacional. Tendo em vista que a crise habitacional não diz respeito apenas a condição de ter um domicilio, mas um lugar em que há qualidade de vida, infraestrutura adequada, efetividade dos direitos fundamentais.

Assim, mais do que esperar por políticas públicas efetivas faz se necessário o emponderamento do individuo para enfrentamento da exclusão habitacional. A modernidade não tolera conformismo, os movimentos acontecem em ritmo acelerado e continuo, em franca

\footnotetext{
${ }^{9}$ (Déficit habitacional Municipal no Brasil, 2013, p. 55).

${ }^{10}$ (...) é aquele particular, localizado em unidade que se destina a servir de moradia (casa, apartamento ou cômodo). Domicílio particular, por sua vez, compreende a moradia de uma ou mais pessoas, na qual o relacionamento é ditado por laços de parentesco, dependência doméstica ou normas de convivência. Por fim, um domicílio é um local de moradia estruturalmente separado (por paredes, muros, cercas entre outros.) e independente, constituído por um ou mais cômodos. (Déficit habitacional Municipal no Brasil, 2013, p. 69). ${ }^{11}$ Disponível em :http://www.cbicdados.com.br/menu/deficit-habitacional/deficit-habitacional-no-brasil Acesso em 02/09/2018.
} 
globalização capitalista e excludente, logo, para os conflitos urbanos decorrentes da disputa de território exige sujeito emancipado ecologicamente e proativo.

\section{Justiça social e cidadania ambiental}

A Revolução Francesa foi um marco histórico, no qual indivíduo passou a exercer determinados direitos frente ao Estado. Com a Declaração de Direitos do Homem e do Cidadão há uma inversão na relação existente entre poder e liberdade, já que o indivíduo passa a ter diversos direitos e garantias que vão limitar o poder do Estado, rompendo a estrutura da sociedade greco-romana, que encarava o homem como um escravo do Estado.

Tal inversão possibilita não apenas o exercício dos direitos políticos, mas a realização dos direitos fundamentais de primeira dimensão.

Por conseguinte, atualmente, a cidadania significa o exercício dos direitos políticos bem como do acesso efetivos aos direitos fundamentais, dentre os quais se encontra o direito ao meio ambiente ecologicamente equilibrado.

Neste diapasão, figura no texto constitucional a soberania, a cidadania e a dignidade da pessoa humana como princípios fundamentais gerais, garantindo, assim, a efetividade do princípio democrático. O princípio democrático, grosso modo, legitima o poder político.

Ademais, o Estado impõe ao cidadão o interesse público já que este detém o monopólio da força, podendo, assim, sobrepor o interesse público ao privado.

Assim, a liberdade como ambiência da cidadania, funciona como um limite ao poder estatal, ao passo que impede o Estado de praticar atos arbitrários que prejudiquem o indivíduo. Sendo a liberdade condição indispensável para a construção de uma sociedade justa e igualitária, já que favorece a participação do indivíduo na tomada de decisão que diz respeito à coletividade.

Cabe salientar que no surgimento da atividade industrial mundial não houve uma preocupação quanto ao bem estar social e as questões ambientais.

A preocupação efetivamente se inicia no momento que a degradação ambiental passa a ser considerada uma ameaça a humanidade, o que gera a necessidade dos países em formularem legislações pertinentes e eficazes.

Nestaesteira, a conscientização ambiental surge como alerta tanto à coletividade como ao Poder Público. 
Partindo desse propósito objetiva-se o desenvolvimento sustentável, ou seja, a utilização dos recursos de maneira que satisfaça a geração atual e as futuras gerações ${ }^{12}$, isso implica em uma responsabilidade intergeracional ${ }^{13}$ do Direito Ambiental, que de forma subjetiva resguarda o meio ambiente.

A partir desta responsabilidade pode-se perceber o princípio da solidariedade numa dimensão intergeracional (mas sem desconsiderar a importância da solidariedade também no plano intrageracional), pois há um vinculo elementar na relação traçada entre o comportamento das gerações humanas contemporâneas para com o ambiente e os recursos naturais e a qualidade (ou mesmo viabilidade) da vida das gerações futuras ( FENSTERSEIFER, 2008, P.89)

Seguindo estes preceitos ambientais, a Constituição Federal de 1988 em seu artigo 225 assevera que cabe ao Poder Público e a coletividade a proteção e preservação do meio ambiente ecologicamente equilibrado para as presentes e futuras gerações.

A partir destes conceitos surge a Justiça Social, que tem como escopo garantir o bem comum, em que procura a satisfação coletiva ${ }^{14}$ e não a individual, através do equilíbrio ambiental.

A justiça social emerge a partir dos movimentos sociais que contestam, as desigualdades e desequilíbrios.

Segundo Acselrad (2013, p. 12), muitos movimentos sociais construíram, a seu modo, neste período, aquilo que constitui a dimensão ambiental específica às suas lutas, convergindo na denúncia da desigualdade ambiental ${ }^{15}$. Neste contexto, os sujeitos das lutas por justiça social ressaltam a existência de uma "irresponsabilidade organizada" nas palavras de Ulrich Beck (1992), mas classista, posto que os grandes projetos hidroelétricos, minerários e monoculturaisexpropiramde seus recursos os grupos sociais despossuídos, ao mesmo tempo

\footnotetext{
${ }^{12}(\ldots)$ entende-se que as presentes gerações adquirem um "legado ambiental" das gerações passadas, tendo obrigação de garantir a sua transmissão às gerações vindouras. A equidade intergeracional e a preocupação global com os direitos das futuras gerações ao meio ambiente natural surgiram a partir da Conferência das Nações Unidas realizadas em Estocolmo em 1972" (CARVALHO, 2013, p. 65)

13 "Compreendido de modo científico-cultural isso abrange a perspectiva geracional supra-individual: a conexão entre gerações institui uma comunidade responsável, à qual o indivíduo nem deve, nem pode, se subtrair. Novos textos constitucionais positivos também têm tomado progressivamente consciência da perspectiva das gerações e lançam um olhar para o futuro de um povo e dos seus cidadãos "viventes" com dignidade humana. Isso também gera responsabilidades e deveres" (HABERLE, 2005, p. 128)

14““(..) a inserção do futuro nos processos de tomada de decisão jurídica, em uma interação entre programação condicional e finalística, é fundamental nas reflexões jurídicas acerca dos novos direitos" (CARVALHO, 2013, p.67)

${ }^{15}$ Aceselrad entende por desigualdade ambiental o estado da distribuição de benefícios e males ambientais do desenvolvimento resultante da operação dos mecanismos pelos quais destina-se maior carga dos danos ambientais a grupos sociais de trabalhadores, populações de baixa renda, povos e comunidades tradicionais, grupos étnicos marginalizados e mais vulneráveis. (ACSELRAD, 2009)
} 
em que pouca atenção governamental é destinada a proteger ou remediar o risco sofrido particularmente por grupos sociais menos capazes de se afastar das fontes de riscotrabalhadores e moradores podres residindo ou trabalhando em áreas onde o preço da terra é mais barato e para onde o mercado, apoiado na omissão política do Estado- quando não os próprios projetos financiados e promovidos pelo Estado- destinam sistematicamente as atividades geradoras de risco (ACSELRAD, 2013, p. 11).

\section{Conclusões}

Em suma, procura a justiça social romper com o paradigma da justiça voltadopara a reparação individual para uma justiça com enfoque na coletividade ${ }^{16}$, no bem comum, através de um antropocentrismo alargado, ao passo que não há supremacia de um interesse sobre o outro, mas necessariamente deve existir uma relação de equilíbrio.

A conscientização desvela a realidade, ela não pode existir fora da práxis, ou seja, sem o ato ação-reflexão, constituindo de maneira permanente, o modo de ser ou de transformar o mundo que caracteriza os homens. Segundo Freire (1980) a conscientização é um compromisso histórico e consciência histórica é inserção crítica na história, implica que os homens assumam o papel de sujeitos que fazem e refazem o mundo. Uma nova realidade deve tomar-se como objeto de uma nova reflexão crítica

A cidadania ambiental vem ocorrendo através dos tempos, mesmo que de forma tímida, mas necessária, de maneira que o indivíduo entenda que é preciso mudar. Assim, torna-se cada vez mais necessário consolidar novos paradigmas educativos e de proteção ambiental, principalmente a transformação de atitudes.

Neste sentido, a modificação do modelo de desenvolvimento urbano excludente não depende de leis, mas de transformação sociocultural e política

\section{Referências}

ACELRAD, Henri. Ambientalização das lutas sociais- o caso do movimento por justiça ambiental. In. Estudos Avançados. V. 24, nº 68, 2010.

\footnotetext{
${ }^{16}$ Necessita-se de uma equidade social que pode ser definida como reconhecimento dos direitos de cada um na sociedade. Na pratica, traduz-se em adaptações de regras e/ou políticas e situações e necessidades de grupos específicos, com a finalidade de tornar mas igualitárias as condições de acesso a direitos (educação, saúde, moradia, etc) e de vida de diferentes grupos populacionais (PEREIRA, 2011, p.66)
} 
Apresentação: conflitos ambientais- a atualidade do objeto. In: Conflitos ambientais no Brasil. Rio de janeiro: RelumeDumatá, 2004.

Apresentação: conflitos ambientais e urbanos: debates, lutas e desafios. MACHADO, Carlos R.S. (org). Porto Alegre: EVANGRAF, 2013.

; MELLO, Cecilia Campello do A; BEZERRA, Gustavo das Neves. O que é justiça ambiental. Rio de Janeiro: GARAMOND, 2009.

BECK, U. From Industrial Society to Risk Society: questions of survival, social structure and ecological enlightement.Theory, Culture\&Society, v. 9. P. 97-123,1992.

CARLOS, Ana Fani Alessandri. Espaço-tempo na metrópole: a fragmentação da vida cotidiana. São Paulo: Contexto, 2001. . O lugar no/do mundo. São Paulo: Hucitel, 1996.

FACHIN, Luis Edson. Teoria Critica do Direito Civil. À luz do novo Código Civil Brasileiro. 2 ed. Rio de janeiro: Ed. Renovar, 2003.

FENSTERSEITFER, Tiago. Direitos Fundamentais e proteção do meio ambiente. Porto Alegre: Livraria do Advogado, 2008. p. 209.

FERREIRA, Luiz Felipe. Iluminando o lugar: três abordagens (Relph, Buttimer e Harvey) Boletim Goiano de Geografia. Goiânia, v. 22, nº 01, 2002.

FERREIRA, Regina Fátima C.F. Movimentos sociais, autogestão e a construção da política nacional de habitação no Brasil. In: Autogestão habitacional no Brasil: utopias e contradições. Rio de Janeiro: Observatório das Metrópoles, 2012.

GRAU, Eros Roberto. A ordem econômica na Constituição de 1998. São Paulo. Ed. Malheiros, 1997.

HARVEY, David. A justiça social e a cidade. São Paulo: Hucitec, 1980.

HOLZ, Sheila y MONTEIRO, Tatiana Villela de Andrade. Política de habitacão social e o direito a moradia no Brasil. Diezaños de cambiosenel Mundo, enlaGeografía y enlasCienciasSociales, 1999-2008. Actasdel X Coloquio Internacional de Geocrítica, Universidad de Barcelona, 26-30 de mayo de 2008. Disponível em http://www.ub.es/geocrit/$\underline{\mathrm{xcol} / 158 . h \mathrm{htm}}$

LAYARGUES, Philippe Pomier. Educação ambiental com compromisso social: o desafio da superação das desigualdades. In: LOUREIRO, Carlos Frederico (org). Repensar a Educação Ambiental um olhar crítico. São Paulo: CORTEZ, 2009.

LEFEBVRE, H. O direito à cidade. São Paulo: Centauro, 2008.

MARICATO, E. O estatuto da cidade periférica. In: O estatuto da cidade comentado. São Paulo: Ministério das Cidades/Aliança das Cidades, 2010.

. Reforma urbana: limites e possibilidades- uma trajetória incompleta. In:

Globalização, fragmentação e reforma urbana: o futuro das cidades brasileiras na crise. Rio de Janeiro: Civilização Brasileira, 1996.

. As metrópoles brasileiras e a globalização neoliberal.In:Brasil, sociedade em movimento. São Paulo: Paz e Terra, 2015.

MARQUES, José Roberto. Meio Ambiente Urbano. Rio de Janeiro: Forense Universitária, 2005, p.52. 
MEDEIROS, Edvaldo da Silva. Direito urbanístico e a dimensão da sustentabilidade: Cidades sustentáveis, uma exigência para um novo paradigma. In: Sustentabilidade: anais de textos selecionados do $5^{\circ}$ Seminário sobre sustentabilidade. Curitiba: Juruá, 2011.

MONTEIRO, P. Cultura e democracia no processo de globalização. Revista Novos Estudos. São Paulo: CEBRAP, nº 44, 1996.

SANTOS, Milton. A urbanização brasileira. 5. ed. São Paulo: Edusp, 2005.

.Metamorfoses do espaço habitado. 3 ed. São Paulo: Hucitec, 1994. . O espaço do cidadão. 7 ed. São Paulo: EDUSP, 2012.

SILVA, José Afonso da. Direito Urbanístico Brasileiro. São Paulo: Malheiros Editores, 2008.

STEFANIAK, Luiz João; STEFANIAK, Janeth Nunes. Efetividade do direito á moradia na cidade ilegal. Cadernos de Direito, Piracicaba, V.12, 2012. 